\title{
Utility of an unitary-shredding method to evaluate the conditions and selection of constructional features during grinding
}

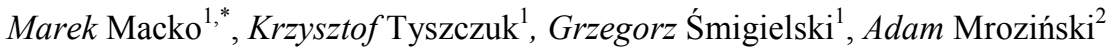 \\ ${ }^{1}$ Faculty of Mathematics, Physics \& Technical Science, Kazimierz Wielki University in Bydgoszcz, Poland \\ ${ }^{2}$ Faulty of Mechanical Engineering, UTP University of Science and Technology, Bydgoszcz, Poland
}

\begin{abstract}
In order to evaluate and improve the efficiency of the process of grinding, various investigations are conducted, based on the relevant research methodology. One of them is the method in which the crushed sample is subjected to single stroke loads. On this basis, the influence of the geometric features of the chipper system and the dynamic process on the efficiency of the grinding is determined. Charpy hammers instrument were used to perform these modifications so that the momentary force of the resistance could be recorded with varying sample alignment, blade geometry changes and others. In addition, it was proposed to use a super fast camera (up to $1200 \mathrm{fps}$ ) to record the deformation of the sample and its destruction, in order to interpretation the burdens there. Under such idealized conditions, a range of variables has been identified that significantly affect the reduction of energy demand during grinding.
\end{abstract}

Keywords: shredding, constructional features, breaking up, energy efficiency

\section{Introduction}

Charpy's hammer is a device that has been proposed to be used to evaluate the suitability of the selected workpiece construction. Basically, this method is used to measure impact strength of materials. By measure of impact, it is possible to mean the ratio of the work involved to the destruction of the sample to the area of the cross-section. There are many possibilities to estimate behaviour of materials, especially dynamic mechanical properties [1-7]. By testing with the hammer, the energy required for the impact fracture (fracture) of the specimen supported by the ends on the two supports is determined by the central pendulum impacting it. Breaking work $\mathrm{K}$ is the potential energy difference of the hammer in the starting position of $\mathrm{K}_{\max }$ and the end of the $\mathrm{K}_{\min }$. The device consists of a base and two columns in which a pendulum with a beater is mounted. The pillars are supported by the pillars on which the sample is laid. This should be done in such a way that the notch is on the same side as the locking supports. When releasing the hook the pendulum with the beater drops from the highest position determined by the angle $\alpha$, thus changing the initial potential $\mathrm{K}_{\max }$ to kinetic. In the impact test, a swing hammer is broken in one hit, the

* Corresponding author: mackomar@ukw.edu.pl

Reviewers: Milan Sága, Ján Vavro Jr. 
notched sample in the middle. This sample is supported by both ends. The energy used to break the sample is expressed in $\mathrm{J}$ - a measure of the impact strength of the material.

Polymer materials, compared to other materials, have a very high durability and resistance to atmospheric conditions, resulting in a long period of biodegradation in the environment [8-10]. They have a weak or medium resistance to mechanical factors depending on their purpose. As regards the preparation of plastics at the stage of processing as well as the development of plastics after the service life, the necessary operation is the comminution [11-14]. Because of problems with detailed estimates of energy demand and high energy consumption, research is being conducted to improve this. One of the test methods is single comminution. Thanks to these tests, one can estimate the energy requirement for a single sample crushing while selecting the appropriate parameters (eg knife shape, knife stroke speed).

\section{Own research}

It was proposed to use impact testing equipment; Charpy hammer (Fig. 1) to assess the impact of changes in geometric features of the chopper operating system. By varying the angle of the blade and the variable materials from which the samples were made, the effects of these changes on the efficiency of the process were assessed.

a)

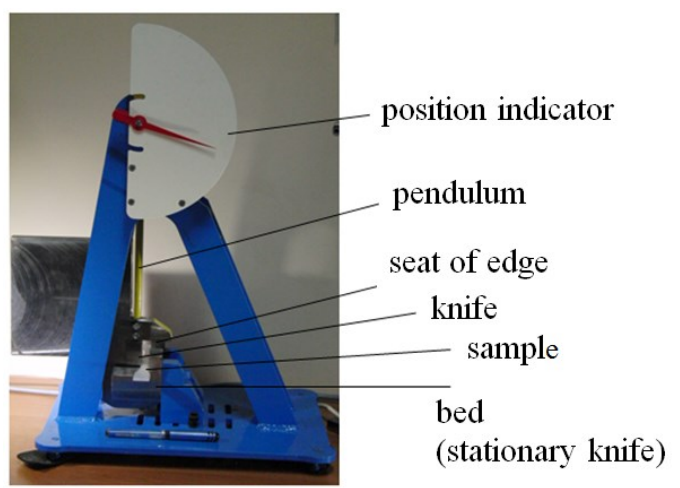

b)

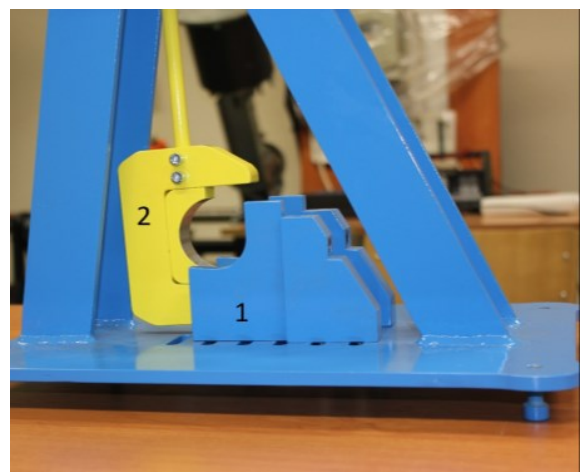

Fig. 1.View of the modified Charpy hammer - a) and working space; 1 - support, 2 - pendulum of modified shape.

In addition, temporary load values were recorded during the process (Fig. 2), and cameras were recorded for fast-change processes at an accuracy of 1200 frames per second (fps) to isolate the key features of the process $[15,16]$. Laboratory tests were performed according to predefined parameters and precision test equipment. The instrumentation used was a four-channel Spider8 system, which was compatible with the computer, whose results could be recorded using a graph in the CATMAN program or LabVIEW application. As a measuring device, the $\mathrm{S} 910 \mathrm{kN}$ force gauge was used. 
a)

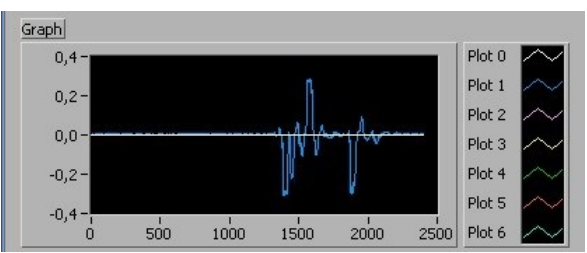

b)

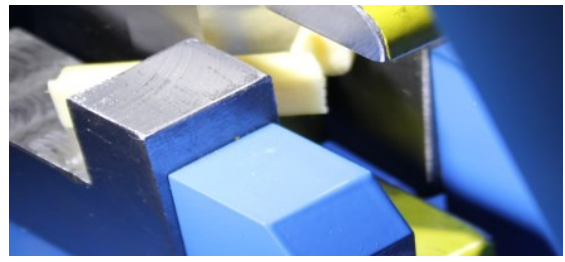

Fig. 2. Example of changes in momentary loads during a single crushing test - a, view of the sample crumbling space $-b$.

Blades of various geometric shapes (blade angles: $90^{\circ}, 80^{\circ}$ and $70^{\circ}$ ) were used in the modified test system. In addition, the pendulum swing angle was observed. Polypropylene samples were tested with $1 \%$ filler (blowing agent).

\subsection{Destruction of polypropylene samples - $1 \%$ filler - blade angle $-70^{\circ}$}

During the test a breakthrough was observed at the point of contact of the sample with the blade. As the blade moves and intensifies the impact surface of the attack plane, after the initial compression of the sample, the fragment of contact plane of the attack plane with the material is torn off (Fig. 3). It has been observed that the deflection of the specimen extends radially from the blade towards the outer edges of the sample. Circles marked by the segments indicate where there are additional shear stresses.

a)

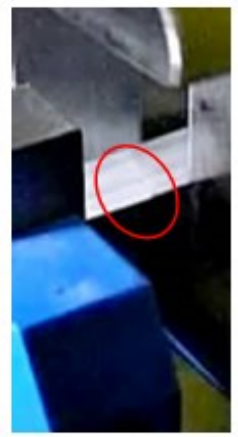

b)

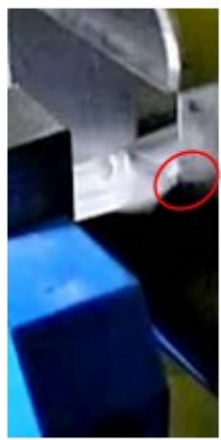

c)

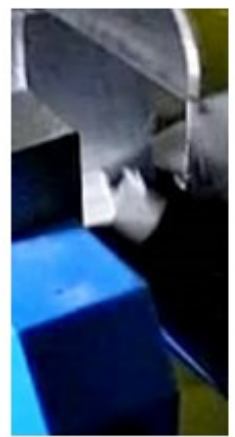

Fig. 3. Destruction of PP sample $1 \%$ at a blade angle of $70^{\circ}$ : a) Blade stroke and crack initiation; b) material rupture associated with rupture of part of the sample to which the racial plane part was active; c) disintegration of the sample fragment.

\subsection{Destruction of polypropylene samples - $1 \%$ filler - blade angle $-80^{\circ}$}

A polypropylene sample with a filler content of $1 \%$ (at the moment of impact) is locally compressed and deformed at the contact area (pictured in red circle) at the time of impact. The sample area is also compressed against the yoke on the blade side. The entire length of the sample is bent and at the same time there is a fragile fracture perpendicular to the edge of the sample. The crack is approximately $1 \mathrm{~mm}$ from the point of impact of the blade in the attack plane. There have also been observed cases of spreading microcracks from the blade 
At an angle of about $82^{\circ}$. In each of these cases, the sample portion was cut between the base (yoke) and the knife application plane.

a)

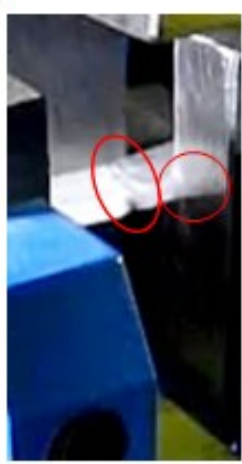

d)

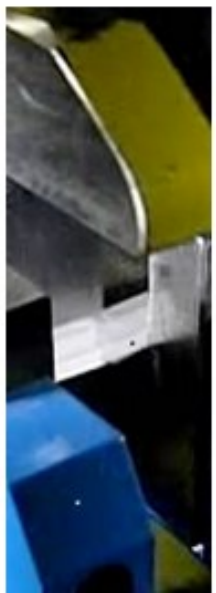

b)

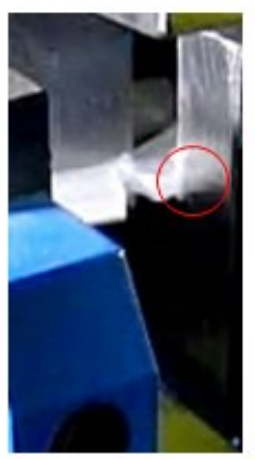

e)

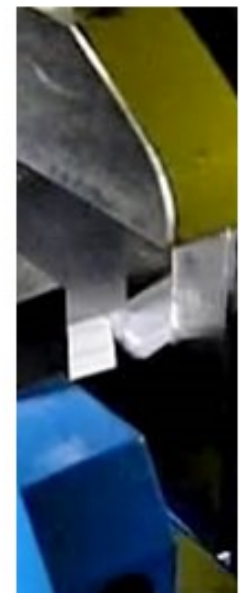

c)

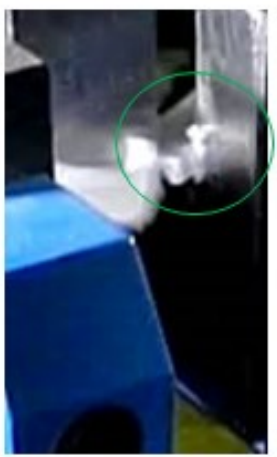

f)

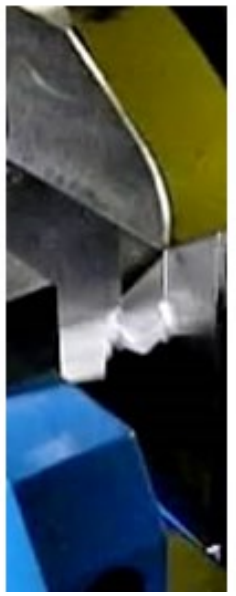

Fig. 4. Destruction of the sample PP1\% at a blade angle of $80^{\circ}$ : a, d) Blade stroke and breakthrough; $b$, e) further compression of the sample (deformation within the solid knife); c, f) Secondary cut off of the beam part.

\subsection{Destruction of polypropylene samples - $1 \%$ filler - blade angle $-90^{\circ}$}

In this case, the fracture propagates between the blade and the edge of the support, but no complete breakthrough occurs. Part of the sample is torn off, and its residues abut against the attack plane and are cut off from the rest of the material (Fig. 5). The figure also shows a semicircular element that disintegrated at the moment of impact. For the blade angle $90^{\circ}$, the impact of the entire surface of the attack plane is affected. Material decontamination occurs in this case in an uncontrolled manner. 
a)

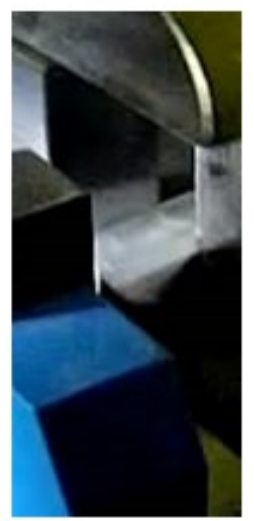

d)

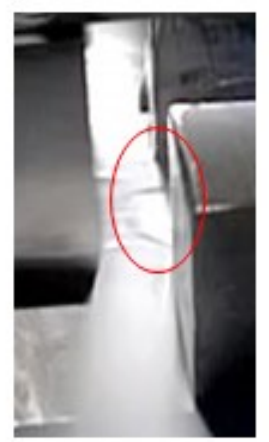

b)

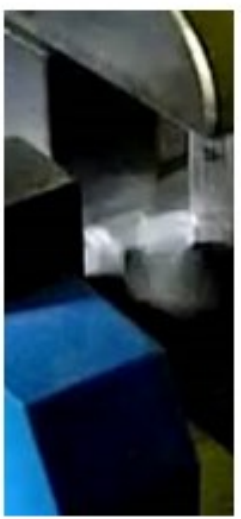

e)

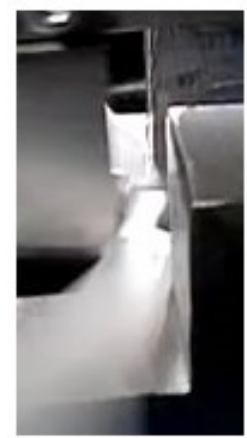

c)

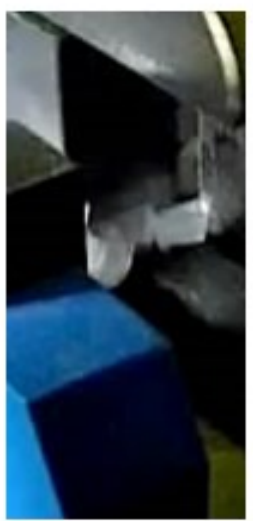

Fig. 5. Destruction of the PP $1 \%$ sample at a $90^{\circ}$ blade angle: a) blade blast and cracks; b) material rupture associated with rupture of part of specimen to which part of the rake surface has been acting; c) ripped sample element; $d, e)$ view in a plane perpendicular to the plane of pendulum movement, (e - notice able detachment of a part of the material in contact with the attack plane).

\section{Conclusions}

In the study, a breakthrough could be observed at the moment the blades were brought closer to the sample. As the knife moves and significantly increases the impact surface of the attack plane, after the sample has been compressed, a portion of the rake face contact with the material is torn apart. Research has shown that the specimen bends radially from the blade towards the outer edges of the sample. A polypropylene sample with a filler content of $1 \%$ (tensile test strip) at the time of impact is subjected to local compression and deformation at the point of contact. A sample of the yoke on the side on which the blade works is also squeezed. The whole surface is bent. At the same time, the brittle fracture is perpendicular to the edge of the sample. Cracks appear approximately $1 \mathrm{~mm}$ from the area where the blade hits the blade in the attack plane. There are also cases of spreading microcracks from the blade at an angle of about $82^{\circ}$. Each time in this type of situation, a sample of the sample is cut between the base (yoke) and the plane of application of the knife. In this case, the cracks come between the blade and the edge of the support. However, there is no complete breakthrough of the sample. Its part is torn off, and the residue is based on the plane of attack. It comes to cut from the rest of the material. One of 
the semicircular elements is disintegrating at the moment of impact. For the angle of the $90^{\circ}$ blade, the entire surface of the attack plane can be observed. Material dehiscence is uncontrolled for this test.

These studies confirm the complexity of the processes that affect the grinding of polymeric materials. A decisive factor in the de Cohesion process and the amount of energy demand is the angle of the knife blade. If the sample is made of polypropylene with $1 \%$ filler content, the energy demand varies, depending on what is the angle of the blade. This is confirmed by observations of the course of the phenomenon, and more precisely the optimally oriented stresses that appeared at a blade angle of $70^{\circ}$. For a blade of $80^{\circ}$, the fragmentation has changed. In addition to the original breakthrough, there were also observed associated stresses which resulted in further cracks in the plane of application. A piece of sample material was located between the breakthroughs. In the case of a knife whose blade reaches the $90^{\circ}$ angle, it does not only break the middle part of the sample (without breakthrough). In addition, it had its rotation and slip between the blades. Under the conditions of energy tests, no breakthrough occurred at the horizontal alignment of the sample. In other cases, it had optimum disintegration. After analysis the results of the research it is possible to draw conclusions about the nature of the structure. Of course, for any material, these will be different conclusions, because the parameters will be different. It is important to capture the sample in detail, since only then can you choose (looking through the prism of minimizing energy demand) material variant. In theory supplemented by practice, we notice that Charpy's hammer is uncomplicated in design, but it is worth considering its modifications - as in the case of this study. It can make it possible to get smaller deviations in individual measurements, which translates into their accuracy.

\section{References}

1. Bauer, D. Wustenberg, Fracture Behavior of Polypropylene under Dynamic Cutting and Shearing. Actions in Granulators Chemical Engineering \& Technology 25 (11), 1047-1051 (2002)

2. J. Flizikowski, Rozdrabnianie tworzyw sztucznych. WMN - ATR Bydgoszcz, (1998)

3. H. Kalman, M. Hubert, E. Grant, Y. Petukhov, M. Haim, Fatigue behavior of impact comminution and attrition units. Powder Technology 146, 1- 9 (2004)

4. M. Sága, P. Kopas, M. Uhríčik, Modeling and experimental analysis of the aluminium alloy fatigue damage in the case of bending - torsion loading. Procedia Engineering 48, 599-606 (2012)

5. M. Sága, R. Bednár, M. Vaško, Contribution to modal and spectral interval finite element analysis. Vibration Problems ICOVP 2011, Springer Proceedings in Physics 139, 269-274 (2011)

6. M. H. Pahl, Zerkleinerungstechnik. Praxiswissen Verfahrenstechnik. Mechanische Verfahrenstechnik: Auflage, Leipzig, (1997)

7. F. K. Wittel, Single particle fragmentation in ultrasound assisted impact comminution. Granular Matter, Springer-Verlag (2010)

8. T. Rydzkowski, Properties of recycled polymer mixtures obtained in the screw-disc extrusion process. Polimery 201156 (2), 135-139 (2011)

9. T. Klepka, Construction of axial-symmetric polymeric extrudates of complex forms. Polimery 200853 (5), 390-395 (2008) 
10. K. Pepliński, P. Czyżewski, D. Górecki, D. Sykutera, M. Bieliński, Selected geometrical features and strength indicators of elements manufactured by fused deposition modeling technology. Polimery 201762 (3), 198-207 (2017)

11. J. Flizikowski, T. Topoliński, M. Opielak, T. Tomporowski, A. Mroziński, Research and analysis of operating characteristics of energetic biomass micronizer. Eksploatacja i Niezawodność - Maintenance and Reliability 17 (1), 19-26 (2015)

12. A. Tomporowski, Filling model for the working multi-disc biomass grain grinding unit. Archive of Mechanical Engineering 59 (2), 155-174 (2012)

13. M. Macko, Metoda doboru rozdrabniaczy wielokrawędziowych do przeróbki materiałów polimerowych. Wyd. UKW, Bydgoszcz, (2011)

14. M. Macko, Economic-energetic analysis of multi-edge comminution of polymer recyclates. Przemysł Chemiczny 92 (8), 1499-1502 (2013)

15. G. Śmigielski, W. Toczek, R. Dygdała, K. Stefański, Metrological analysis of precision of the system of delivering a water capsule for explosive production of water aerosol. Metrology and Measurement Systems 23 (1), 47-58 (2016)

16. M. Sasso, M. Fardmoshiri, E. Mancini, M. Rossi, L. Cortese, High speed imaging for material parameters calibration at high strain rate. Eur. Phys. J. Spec. Top. 225 (2), 225 - 295 (2016) 